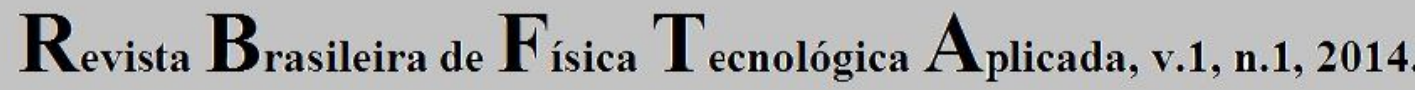

\section{Por uma Blogosfera educativa: formalidade e informalidade no ensino de Física sob uma nova perspectiva de filmes e animações hands-on.}

\author{
Para una blogosfera educativa: la formalidad y la informalidad en la enseñanza de la Física \\ desde una nueva perspectiva de las películas y animaciones hands-on.
}
For an educational Blogosphere: formality and informality in Physics teaching from a new perspective of films and animations hands-on.

Marcos Cesar Danhoni Neves ${ }^{1}$ Eloá dei Tós Germano, Ana Claudia Danhoni Neves, Josie Agatha Parrilha da

Resumo: O presente trabalho apresenta uma pesquisa envolvendo a questão da produção de filmes e animações didáticas e contextualizadas na história da ciência para o ensino de Física. É feito um resgate histórico dos grandes projetos que envolveram o uso didático e criativo de experimentos e fenômenos tratados a partir de uma perspectiva de animações, curta-metragens e filmes de apoio aos conteúdos da ciência física. Será explorado o programa Algodoo como possibilidade de produção de animações do tipo hands-on. Para tanto, baseado em pesquisa sobre concepções física entre estudantes sobre um hipotético experimento de gravitação - um poço que perfura toda a Terra - é traçado um roteiro que vai do plano inclinado ao movimento pendular.

Palavras-chave: ensino de física; história da ciência; filmes; linguagem verbo-visual.

Resumen: En este trabajo se presenta un estudio de la cuestión de la cinematografia, de la enseñanza y la contextualización basada em la historia de la ciencia. Relata la historia de los grandes proyectos que implican el uso de experimentos educativos, creativos y fenómenos tratados desde una perspectiva de animaciones, cortometrajes y películas apoyado em el contenido de la ciencia física. El programa Algodoo será explorado como una posibilidad de producir animaciones hands-on. En base a la investigación sobre las concepciones físicas entre los estudiantes acerca de un experimento hipotético de la gravitación - un pozo que perfora toda la tierra - se trazó un script di enseñanza del plano inclinado al péndulo.

Palabras clave: enseñanza de la física; historia de la ciência; películas; lenguaje verbal-visual.

\begin{abstract}
This paper presents a question of research involving filmmaking and didactical animations in the physics teaching in a contextualized situation using the history of science. A survey of the history of important projects involving the use of educational and creative experiments and phenomena is made from a perspective of animations, short films as a support of the contents of physical science. A program named Algodoo will be explored as a possibility of producing animations hands-on. Based on a research on physical conceptions among students about a hypothetical experiment of gravitation - a free fall of an object in a whole earth - it is planned a kind of script from the inclined plane to pendulum's motion.
\end{abstract}

Keywords: physics teaching; history of science; films; verbo-visual language. 


\section{Introdução}

O trabalho que ora se inicia, foi baseado em resultados de pesquisas iniciadas há mais de 40 anos, relativas às ideias dos estudantes acerca de fenômenos físicos (ZA'ROUR, 1975; VIENNOT, 1979), constituindo-se num divisor de águas a respeito de dar atenção àquilo que era sempre taxado de "erros" e considerado sempre negativamente. Estudar a forma como os estudantes elaboram seus próprios conhecimentos é também ela própria uma forma legítima de conhecimento, avaliação e aprendizagem de pesquisa.

Quando foi publicado o primeiro artigo (ZA'ROUR, 1975) sobre os conceitos "equivocados" (misconceptions) dos estudantes, ainda não existia qualquer teoria sob a qual houvesse algum sentido em se falar de "ideias" (no sentido de "esquemas de conhecimento") dos estudantes. $\mathrm{O}$ ensino era pensado como uma comunicação de conhecimentos sobre mentes do tipo tabula rasa, e os insucessos eram atribuídos aos "erros" ou à quase "estupidez" dos estudantes.

O comportamentalismo sugeria um ensino que, mediante estímulos oportunos, produzisse de modo eficiente. Para tal fim, eram desenvolvidas oportunas "tecnologias didáticas" baseadas em "métodos científicos" (que eram creditados, em sua maioria, a um modus operandi de Galileu Galilei). Cientistas interessados na transmissão do conhecimento e nos problemas epistemológicos e psicológicos do desenvolvimento do conhecimento, tinham desenvolvido hipóteses sobre a natureza de um conhecimento comum (BRONOWSKI, 1985) e salientado sobre a importância em se refletir sobre os "erros" dos estudantes (ENRIQUEZ, apud ALBANESE et al., 1997). Porém, ainda inexistia uma referência empírica para atribuir a tais hipóteses uma validade científica.

Após o trabalho de Viennot (1979), que trazia os resultados de uma pesquisa sobre "raciocínio espontâneo em dinâmica elementar", o interesse dos estudiosos fez desabrochar um filão de pesquisa no qual o estilo das perguntas postas aos estudantes estimulava a explicitação de respostas do tipo "não-padronizadas" (diferentes das noções comumente aceitas pelas teorias e modelos vigentes).

\section{Investigando um tema: gravitação}

Desde os trabalhos de Viennot (1979), houve um florescer de pesquisas em várias partes do mundo usando como metodologia perguntas para relevar dados de interesse (questionários do tipo "papel e caneta" com respostas abertas ou de questões múltiplas; entrevistas clínicas do tipo piagetiano) e recursos para a análise das respostas encontradas. 
Desta busca nasceu um conjunto de dados empíricos que apresentavam duas características muito importantes:

a) uma invariância cultural (estudantes de vários países respondiam do mesmo modo ou quase - a perguntas similares);

b) uma independência substancial das respostas para o tipo de ensino recebido.

Diante dessas características, houve uma grande necessidade em se procurar uma explicação para os dados empíricos reunidos em uma referência teórica que pudesse dar conta dessa "invariância cultural" e, ao mesmo tempo, dessa "independência" em relação às respostas encontradas. As hipóteses de uma ciência de senso comum adquirem então um significado científico uma vez que prefigura um modelo de aprendizagem do tipo construtivista.

De qualquer modo, os dados "empíricos" assinalam a passagem, no ensino, de uma fase pré-paradigmática para uma fase paradigmática. Isto pode ser notado pela substituição da palavra misconception (algo como "conceito errado"), que denota a falsidade de tais ideias com respeito ao conhecimento científico, por palavras que expressam o conhecimento não em termos de "conhecimento científico", mas de um "conhecimento alternativo" ("física ingênua”, "física espontânea”, “concepções alternativas”, "representações mentais"), alicerçado sobre uma hipótese construtivista do conhecimento.

É neste corte epistemológico que se elaborou, baseado numa longa experiência de realização de produção de filmes e animações em Física, algumas perguntas paradigmáticas para entender como os estudantes alicerçam suas concepções alternativas.

Para exemplificar, reproduziu-se uma velha questão de pesquisa acerca do comportamento de um corpo sólido deixado cair no interior de um poço vertical que perfure toda a Terra (ALBANESE et al, 1997). As situações são todas hipotéticas e as questões do poço vertical e do poço "horizontal" absolutamente equivalentes, posto que em ambas, o poço perfura o centro da Terra. Na situação de "poço inclinado", não se passa pelo centro.

A Tabela 1, envolvendo pesquisa de uma sala de 40 (quarenta) alunos de graduação em Física (Licenciatura e Bacharelado) do $1^{\circ}$ ano de curso, mostra os percentuais de conformidade com os esquemas aceitos culturalmente pela comunidade científica (esquemas galileano-newtoniano) para a questão com as três vertentes de exploração conceitual. Respostas que não tinham um padrão "alternativo" ou conceitual galileano-newtoniano foram classificadas de "ambíguas". 
Estes resultados expressam por si a forma conceitualmente distorcida em que o tema gravitação é tratado no Ensino Médio que interessará ao trabalho ora em discussão. Quando o ensino centra foco somente em sua formulização/axiomatização de leis, no caso da gravitação, uma força que varia com o inverso do quadrado da distância leva inevitavelmente à conclusão de que o sólido deixado cair no interior do poço (numa situação idealizada abstraindo-se de qualquer tipo de atrito e temperaturas) ficará preso ao centro da Terra, e não oscilará como um oscilador harmônico como seria a previsão culturalmente determinada pela comunidade científica.

\begin{tabular}{|c|c|}
\hline Esquema de respostas & $\begin{array}{c}\text { Percentual e respostas entre alunos de } \\
\text { graduação }\end{array}$ \\
\hline Galileano-newtoniano & 3,98 \\
\hline Alternativo & 72,02 \\
\hline Ambíguo & 24,00 \\
\hline
\end{tabular}

Tabela 1: poço vertical

\begin{tabular}{|c|c|}
\hline Esquema de respostas & $\begin{array}{c}\text { Percentual e respostas entre alunos } \\
\text { de graduação }\end{array}$ \\
\hline Galielano-newtoniano & 4,85 \\
\hline Alternativo & 72,65 \\
\hline Ambíguo & 22,50 \\
\hline
\end{tabular}

Tabela 2: poço "inclinado"

\begin{tabular}{|c|c|}
\hline Esquema de respostas & $\begin{array}{c}\text { Percentual e respostas entre alunos } \\
\text { de graduação }\end{array}$ \\
\hline Galielano-newtoniano & 3,82 \\
\hline Alternativo & 70,10 \\
\hline Ambíguo & 26,08 \\
\hline
\end{tabular}

Tabela 3: poço "horizontal"

Antes de dar tratamento adequado a essa questão, elaborando filmes didáticos e animações capazes de envolver as noções de conhecimento alternativo e obstáculos epistemológicos decorrentes, fez-se necessário um resgate histórico dos grandes projetos de ensino de Física que usaram de tecnologias de informação e da história da ciência para elaborar um ensino de Física dinâmico, histórico e contextual.

\section{A produção verbo-visual para o ensino de Física}

O PSSC (Physical Sciences Study Committee) foi o grande Projeto de Ensino de física que marcou a década de 60 do século passado, caracterizado pelo uso intenso de uma série de filmes didáticos (PSSC, 1964) que procuravam reunir a tecnologia audiovisual de época com as técnicas de cinematografia (BRYAN, 1987) e de professores de excelente formação. O 
PSSC foi um dos programas realizados na esteira do atraso tecnológico e científico norteamericano em relação à corrida espacial. Os russos tinham colocado um satélite no espaço, o Sputnik, e os norte-americanos estavam aquém desta tecnologia.

Os filmes do PSSC mantinham um rígido programa de Física por meio da experimentação. Os recursos mais modernos da época, envolvendo técnicas de slow-motion, fotografias estroboscópicas, etc., foram utilizados nos filmes e Super-8 (looping) no sentido de serem utilizados em salas-de-aula, incluindo-se aí a possibilidade concreta de tomada de medidas nos experimentos filmados.

Retalhos desses filmes sobrevivem hoje em vários projetos ou vídeos: Harvard Project Physics (PROJECTO FISICA, 1980), "Cosmos" (SAGAN, 1980), The Mechanical Universe (GOODSTEIN et al, 1989), Physics: Cinema Classics (BRYAN; PHYS.CLAS., 1992).

Essas últimas referências retiraram muito da visão excessivamente empirista do antigo PSSC, incluindo tópicos de história da ciência ou de uma linguagem midiática múltipla. Porém, todos estes programas que usam filmes ou documentários, possuem uma mesma linha diretiva: eles procuram ser auto-suficientes, ou seja, procuram "passar o recado ou ponto" mesmo na ausência do professor. São filmes de média e longa metragem, baseados numa longa sequência, buscando abarcar todos os conteúdos de física.

Na esteira do PSSC, foi criado o Harvard Project Physics, como parte de uma amplo programa de reforma curricular norte-americana no sentido de recriar na escola secundária um ensino de física compreensível, interativo e com a história da ciência como tema transversalizador das atividades didáticas. O projeto esteve em atividade de 1962 a 1972, e produziu uma série de textos que foram usados em salas de aula na década de 1970 à década de 1980. O projeto foi gerenciado pela Universidade de Harvard, mas trabalhou sua proposta inovadora em milhares de escolas, usando educadores de todo o país.

O projeto "Harvard", de amplo espectro, tinha como coordenadores James Rutherford, coordenadora do projeto e Gerald Holton, que garantiu a inovação da inserção da história da ciência no ensino de Física.

Os conteúdos atrelados ao Harvard Project Physics eram reforçados por uma série de filmes herdados do antigo PSSC na base de ealing loops (filmes sem fim), com projetores específicos e baseados em técnicas envolvendo slow-motion e imagens sequenciadas, para que fosse possível a professores e alunos a tomada de medidas em diferentes experimentos de física.

RBFTA, v.1, n.1, maio/junho de 2014, p. 42 
Dos filmes ealing loop à contemporaneidade, a produção de experimentos virtuais baseados em animação Java, algodoo e outros programas de animação digital democratizaram o acesso e, especialmente, a produção própria de filmes (ZOLLMAN, 2002), de animações e simuladores virtuais, que hoje são encontrados em sites próprios de universidades, mas, de forma amplamente disseminada, nas redes sociais e especialmente no extenso universo daquilo que poderíamos batizar de "blogosfera educativa". Estes filmes, uma espécie de hands-on ("mão na massa") em Física, podem capturar a imaginação dos estudantes e sua potencial criatividade potencial em simulações virtuais de grande valia para o uso no Ensino de Física formal e/ou informal.

\section{Problemas e soluções para a pesquisa em linguagens verbo-visuais e animações educativas}

O estado da arte do uso de mecanismos informais de ensino e/ou divulgação da Física de qualidade está ainda por fazer. É necessário avaliar em ampla escala a existência de uma blogosfera e suas diferentes origens e ancoragens metodológicas (simulação, ilustração, etc.) e sua efetividade para o ensino de física e suas aplicações tecnológicas.

É necessário ainda um árduo trabalho para mapear a blogosfera educativa que gravita ao redor de instituições de ensino ou derivada de alunos/ex-alunos que buscaram no ensino informal estratégias de mudanças no ensino formal de física/ciências.

Também é necessário historiar de forma precisa a evolução dos filmes científicos para uso em projetos de grande e médio porte (PSSC, Harvard Project Physics, Cosmos, The Mechanical Universe, RAI (VICENTINI et al, 1980), FÍSICA AUTO-INSTRUTIVA, SPECCAPES, etc.). Outro aspecto historiográfico necessário seria aquele de recuperar para novas mídias todo o acervo dos ealing loops que hoje se encontra perdido mesmo na web, uma vez que desapareceram da cultura educativa formal e informal: passagem da mídia super-8 para imagens digitalizadas que poderiam servir de banco de dados para serem disponibilizadas em sites específicos e apropriados de instituições ou de blogs educativos.

Importante para estimular alunos a participar de projetos de criação virtual mediante o uso de computador, seria produzir animações $J A V A$, com tutoriais para a auto-replicação de novas possibilidades de experimentos virtuais que possam dar apoio à uma ampla gama de instrumentação para o ensino. Nesse sentido, seria apropriado produzir blogs exclusivos, com marcadores de acesso, e de amplo espectro educacional (links com diferentes instituições nacionais e internacionais, especialmente, em contato com a Harvard University, para a recuperação digital dos filmes iniciais tipo ealing loop) 
Em toda pesquisa instrumental, seria necessário recuperar e/ou planejar atividades de simulações virtuais baseados em experimenta crucis que ilustram a história da ciência e da técnica, encontrando um vocabulário próprio característico da mediana de blogs analisados por meio de metodologias qualitativas de análise e que pudessem possibilitar a criação de uma linguagem característica para uma blogosfera educativa informal.

\section{Dos temas motivadores e de suas produções virtualizadas}

Uma analogia que entende-se poder ser utilizada para o atual ensino de Física é aquela de um professor dessa disciplina, quando pretende ensinar aos seus alunos sobre a oscilação de um pêndulo. Normalmente desenha a trajetória da massa pendular no quadro e se apropria das imagens do livro didático, "ilustrando o fenômeno" com a fórmula específica do período para o movimento pendular. O problema é que, nesse caso, os alunos não têm contato nenhum com a tridimensionalidade da situação. Há praticamente um 'exílio' da situação real.

Quando um professor realiza com seus alunos experiências práticas (BRUNER, 1961), como o simples ato de colocar uma massa para oscilar, esses alunos passam a ter um contato direto com a situação, tornando a atividade como um fato "palpável", concreto. Como o ensino de Física envolve muita subjetividade, seu aprendizado, na escola atual, é sempre realizado de forma teórica, quase sempre desmotivador.

Quando são utilizados experimentos, simulações, softwares e outros recursos do gênero no ensino de Física, transforma-se essa subjetividade em um tipo de objetividade que pode colaborar de maneira mais eficaz na aprendizagem dos alunos. Acoplar objetividades (experimentação) a subjetividades (simulação, virtualidades) envolve uma grande carga de interdisciplinaridade necessária à educação contemporânea de qualidade.

Já foram realizados trabalhos envolvendo os motores de produção de animação, slowmotion, e simuladores de movimentos, e, como exemplo, citou-se uma série de figuras abaixo produzidos para um projeto SPEC-CAPES (SAVI et al., 2002), demonstram quase passo-apasso (Figuras 1, 2 e 3) o processo de concepção - geração - animação - arte final de concepções, experimentos virtuais ou experimenta crucis: no caso presente, a concepção de impetus adquirido (Figura 4), pêndulo de Foucault idealizado (Figura 5), antiperistasis em ação no vôo de uma flecha (Figura 6), plano inclinado galileano (Figura 7), quedas iguais em ambiente onde é realizado o vácuo (Figura 8). 


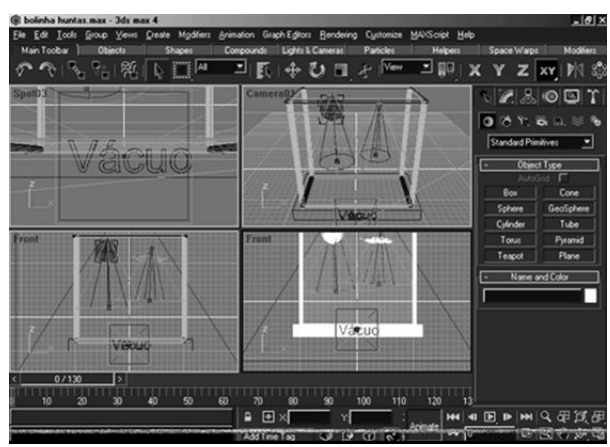

Figura 1: criando o esboço virtual

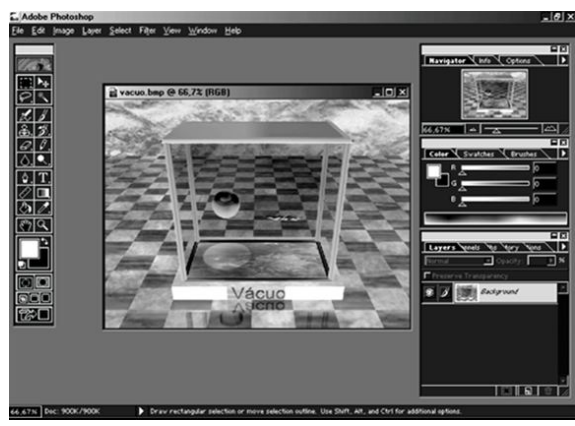

Figura 3: processo semi-final da animação

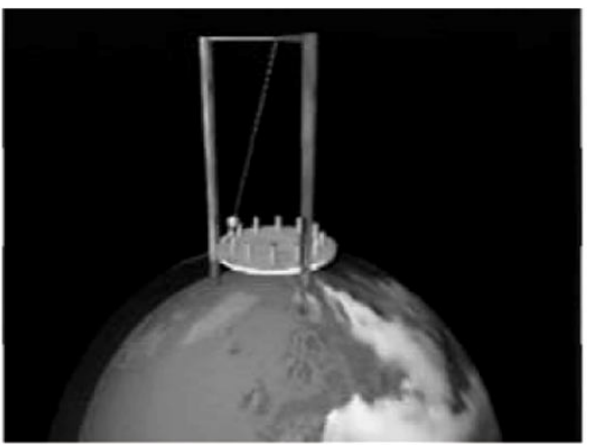

Figura 5: O pêndulo de Foucault sobre o pólo sul

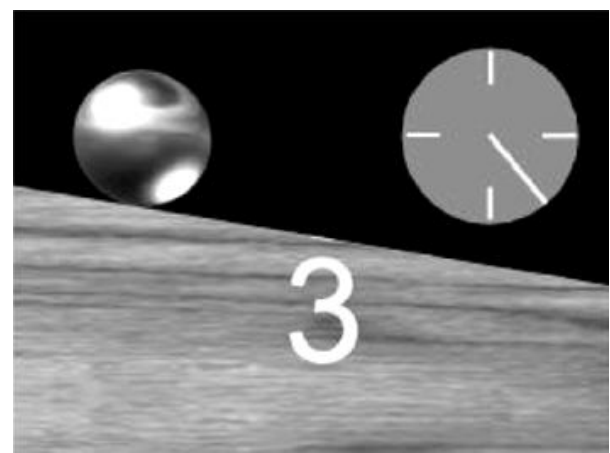

Figura 7: O plano inclinado Newtoniano

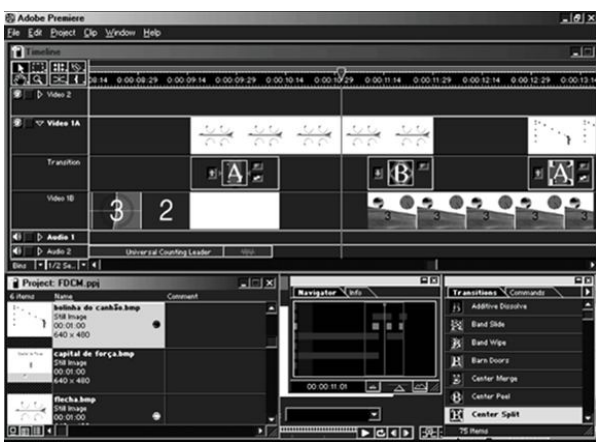

Figura 2: passos da animação

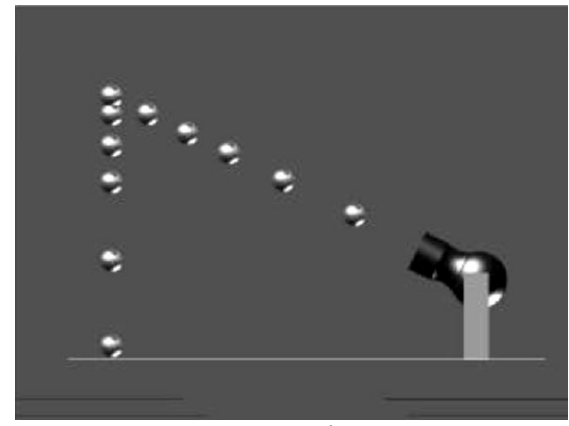

Figura 4: animação do ímpetus adquirido num tiro de canhão

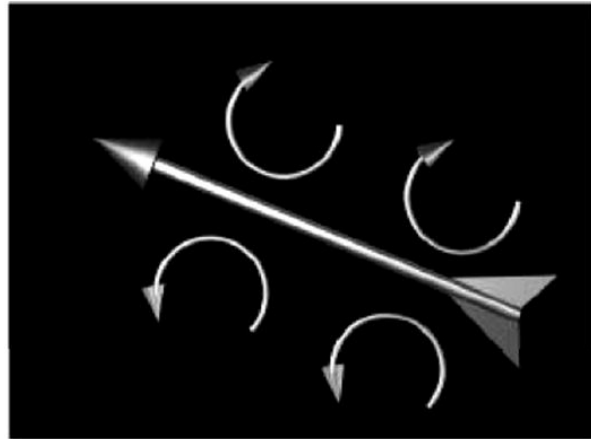

Figura 6: A antiperistasis no vôo da flecha

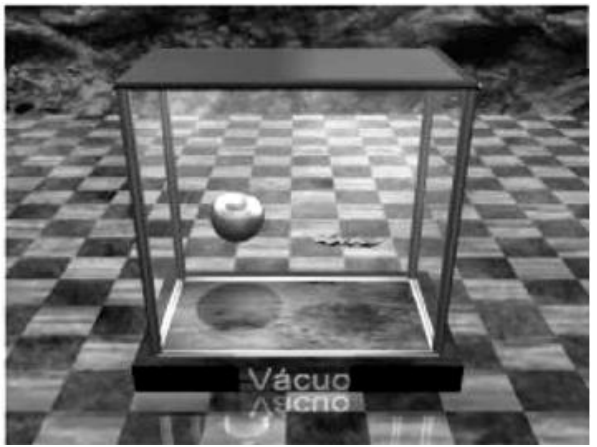

Figura 8: A queda de graves diferente no vácuo 
Esta série de imagens, envolvendo editores de imagens stop-motion demonstram a potencialidade de diferentes recursos computacionais que podem simular, ancorados na história da ciência, experimentos que nunca tinham sido realizados em laboratórios didáticos.

\section{Problemas virtuais utilizando o programa $A L G O D O O$}

Para demonstrar as possibilidades anteriormente elencadas, especialmente o hands-on, usou-se o programa de representações gráficas Algodoo by Alogryx versão 2.1.0 (ALGODOO, 2014). Trata-se de um software que permite realizar simulações em duas dimensões, criando um ambiente interativo, onde experimentos podem ser criados na forma de desenho animado lúdico, fazendo uso da Física para exemplificar fenômenos variados de nosso mundo contingencial e, consequentemente, incentivando os alunos a desenvolverem seus próprios potenciais criativos. O programa Algodoo tem sido utilizado em escolas de primeiro mundo e é disponível gratuitamente para download, no site: <http://www.algodoo.com/download>.

O software apresenta uma interface dinâmica e atrativa dispondo de ferramentas que permitem trabalhar com a construção de corpos rígidos, fluidos, engrenagens, molas, dobradiças, motores, raios de luz, lentes e ótica, o que pode ser de grande utilidade para o desenvolvimento das aulas para os docentes dessas diferentes subáreas da Física.

Nele é possível alterar a força gravitacional, a restituição dos corpos, os coeficientes de atrito, os índices de refração, as diferentes densidades, as camadas de colisão, os controle da aceleração, as texturas (que permitem colocar diferentes imagens de objetos), cores, distâncias, velocidades da luz de um laser em diferentes meios, diferentes valores de velocidade, força, limites de ruptura, impulso, direção e controle de uma dobradiça/motor, forças constantes, fator de amortecimento e inúmeros outros recursos que proporcionam aos seus usuários obterem resultados variados e interessantes para análise.

Desde o inicio da década de 80, pesquisadores da área de educação têm-se voltado à questão de introduzir ou não as novas tecnologias em sala de aula. Entende-se que os meios por si só, são ineficientes, quando usados como objeto principal no processo educativo. Porém, quando colocadas a serviço de objetivos, adequados às necessidades do projeto político-pedagógico, podem ser de grande valia.

Acredita-se que um dos principais objetivos do ensino é formar pessoas críticas, criativas, com condições de interagir com o mundo que está à sua volta. Baseado nas dificuldades dos alunos em compreenderem a construção dos conceitos físicos, observa-se que o ideal é utilizar a História da Ciência como instrumento de aprendizagem no sentido de

criar obstáculos epistemológicos envolvidos na construção dos conceitos. A fim de RBFTA, v.1, n.1, maio/junho de 2014, p. 46 
demonstrar este "matrimônio" entre conceito e técnica, numa experiência hands-on physics, usam-se os exemplos da fenomenologia mecânica descrita, começando do plano inclinado, passando ao pêndulo até chegar à noção da força gravitacional, no hipotético experimento do poço que perfura toda a Terra como salientado no início do presente trabalho.

\section{Plano inclinado}

Baseado na descrição sobre o experimento do plano inclinado presente no livro Discorsi intorno a Due Nuove Scienze (GALILEI, 1988), montou-se a seguinte modelagem:

$1^{\circ}$ Passo: desenhou-se um triângulo retângulo, para representar o plano inclinado, como mostra a Figura 9.

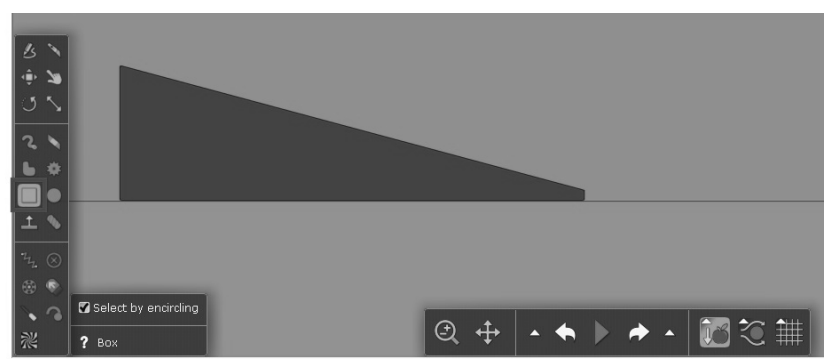

Figura 9: Superficie do plano inclinado

$2^{\mathbf{0}}$ Passo: posteriormente, foi desenhado um círculo, representando uma esfera, sobre o plano inclinado. Foram introduzidas as opções dos vetores, selecionando a força peso, a força normal e o vetor velocidade como mostra a Figura 10, para que quando em movimento, pudesse ser verificado o aumento da velocidade da bola.

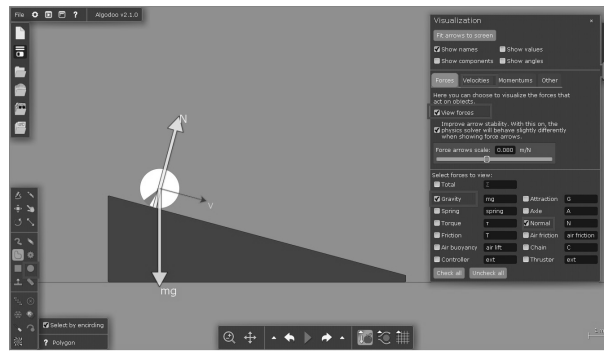

Figura 10: Plano inclinado

Nesta simulação os alunos podem aumentar ou diminuir o ângulo de inclinação, alterar a intensidade da resistência do meio (tanto do ar quanto da superfície), mudar as características do corpo que está sobre o plano inclinado, e verificar o comportamento do corpo ao descer o plano inclinado para cada situação proposta.

Para comprovar a conservação da energia mecânica, usa-se a seguinte modelagem computacional: 
$1^{\circ}$ Passo: ligar dois planos inclinados por um arco, para simular uma rampa, como mostra a Figura 11.

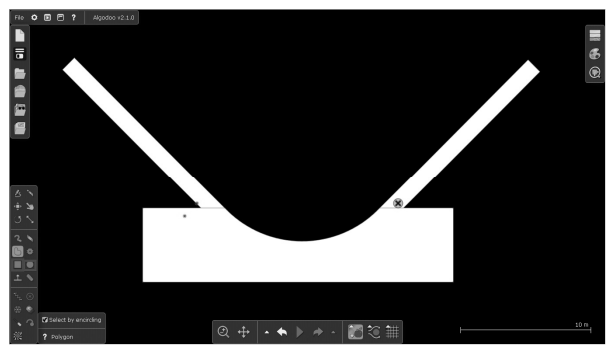

Figura 11: Planos inclinados ligados por um arco

$2^{\mathbf{0}}$ Passo: desenhar uma circunferência sobre o arco e, assim como no plano inclinado simples, acionar a opção dos vetores e do vetor velocidade como mostra a Figura 12. Nessa simulação pode-se verificar a conservação da energia mecânica.

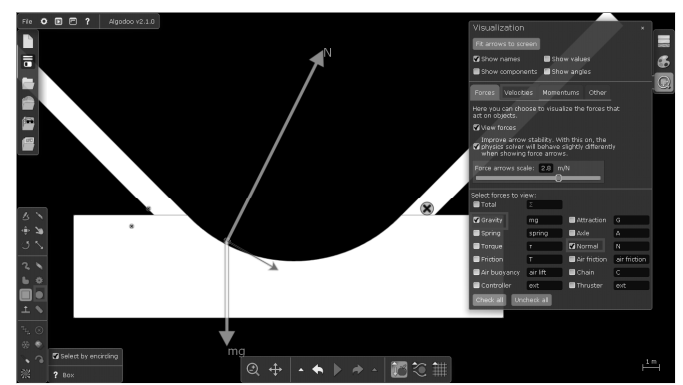

Figura 12: Dois planos inclinados (com os vetores)

Assim como no plano inclinado simples, todas as características citadas podem ser alteradas no intuito de verificar o comportamento das forças e do vetor velocidade para cada situação proposta.

\section{Pêndulo}

No livro Discorsi intorno a Due Nuove Scienze (GALILEI, 1988), como citado anteriormente, Galileu discute o comportamento oscilatório de um pêndulo simples para se chegar ao que hoje chamamos de conservação de energia. Para a modelagem desse experimento, foram utilizados os seguintes passos:

$1^{\circ}$ Passo: foi fixada uma base na forma de retângulo para servir de apoio. Nela foi fixada uma corda, a qual, por sua vez, possuía uma esfera como massa oscilante (Figura 13). 


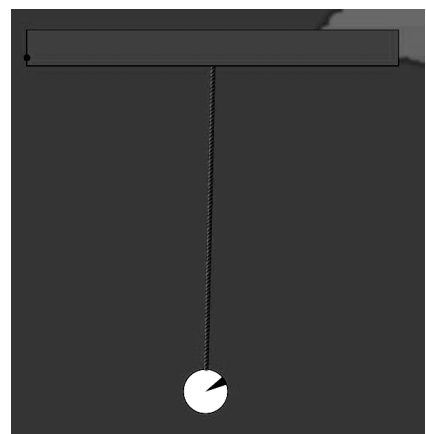

Figura 13: Parte estrutural do pêndulo simples

$2^{\circ}$ Passo: foi ativado o vetor da força peso e da velocidade (Figura 14) para que, quando posto em movimento, pudessem ser realizadas algumas análises importantes para a compreensão do fenômeno oscilante.

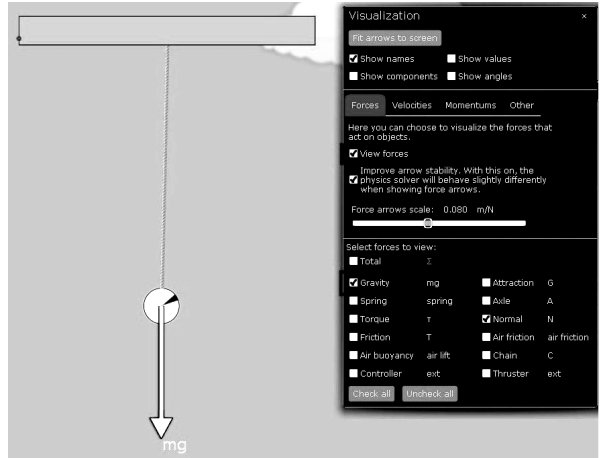

Figura 14: Pêndulo com vetores

A Figura 15 mostra o pêndulo já em movimento. Pode ser verificada a conservação da energia mecânica, pois quando solto de certa altura a massa retorna ao mesmo ponto de partida.

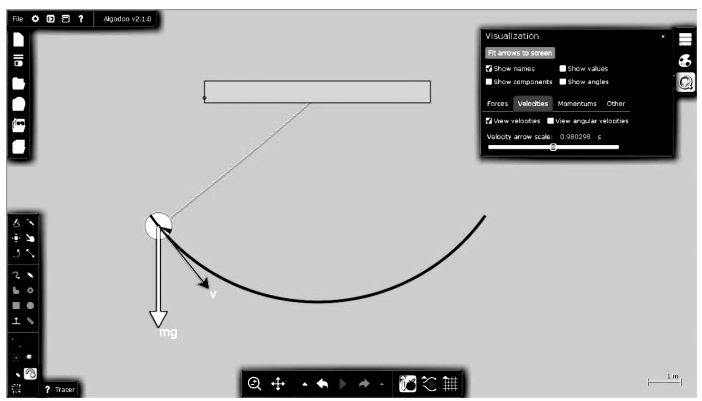

Figura 15: Pêndulo em movimento

Essa modelagem permite que a densidade do corpo suspenso, o comprimento do fio e o valor da resistência do ar sejam alterados para verificar a influência de cada variável durante o movimento. 
Com a mesma estrutura, apenas adicionando um obstáculo (prego) à trajetória do pêndulo, verificou-se a descrição feita por Galileu em seu livro Discorsi intorno a Due Nuove Scienze (GALILEI, 1988), quando discute a experiência de um pêndulo interrompido por um prego (Figura 16).

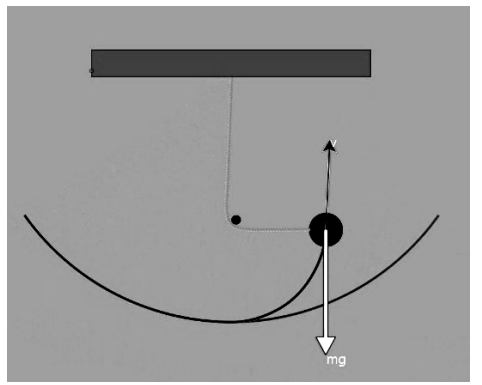

Figura 16: Pêndulo interrompido por um prego

Para concluir a discussão sobre os experimentos de Galileu, foi montado um experimento virtualizado (esquema da Figura 17), onde inseriu-se o pêndulo sobre o plano inclinado. A situação demonstrou com clareza a similaridade dos experimentos e, de forma gráfica e idealizada, que as discussões sobre movimentos pendulares e de corpos rolando em plenos ascendentes e descendentes levariam poucas décadas depois à noção fundamental da conservação da energia mecânica.

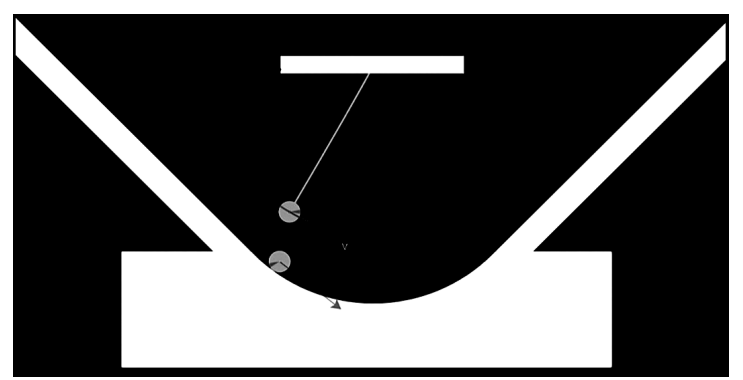

Figura 17: Pêndulo e plano inclinado

\section{Poço na Terra}

Para representar o problema acima muito idealizado, montou-se um esquema computacional no programa Algodoo para que o problema da oscilação pudesse ser verificado de forma mais dinâmica e dramática:

$\mathbf{1}^{\mathbf{0}}$ passo: desenhou-se uma circunferência, representando bidimensionalmente a esfera terrestre. Foi retirado do meio desta representação gráfica um retângulo, para que simulasse a existência de um poço que atravessasse toda a Terra; 
$2^{\circ}$ passo: foram ligadas as duas extremidades, representando o poço, e uma nova circunferência (esfera) foi desenhada para que representasse o corpo que viajaria pelo interior do planeta;

$3^{\text {o }}$ passo: ativou-se então a força gravitacional e desligou-se todo atrito possível, numa situação extremamente idealizada, como mostra a Figura 18.

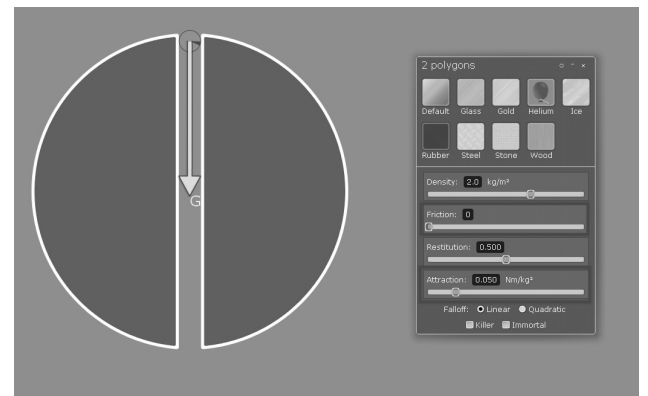

Figura 18: Ativando a força gravitacional

$4^{\mathbf{0}}$ passo: por questões de estética foi aplicado como fundo da circunferência uma imagem do planeta Terra, como mostra a Figura 19.

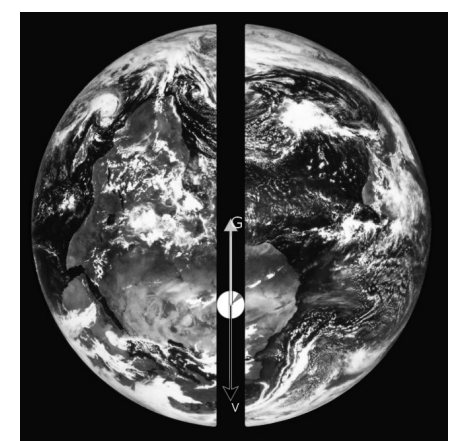

Figura 19: Fundo editado sobre circunferência (planeta Terra - polo sul reconvencionado "para cima")

$5^{0}$ passo: com a simulação já pronta, foram ativados os vetores no corpo de menor massa para que, durante seu movimento, se possa observar sua velocidade e como a força gravitacional atua sobre ele.

As simulações podem ocorrer com ou sem a resistência do ar, sendo que seu valor pode ser alterado conforme se deseja apresentar a situação, demonstrando claramente os efeitos já descritos acima.

\section{Analogia com o sistema massa mola}

Nessa modelagem do poço hipotético que perfura a Terra, foi utilizada a mesma estrutura de um sistema massa mola, como mostra a Figura 20. 


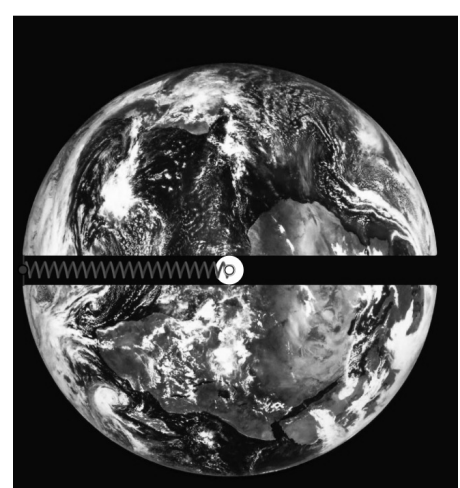

Figura 20: Sistema massa-mola

Aqui o movimento de oscilação pode variar de acordo com o valor atribuído à constante elástica da mola e ao valor atribuído à resistência do ar. Interessante notar que esta analogia leva a interessantes obstáculos epistemológicos, especialmente porque o senso comum tende a prever que a esfera que cai para no centro do planeta devido à ideia da gravitação newtoniana de que "tudo tende para um centro" (ou de que a força é inversamente proporcional ao quadrado da distância que separa o centro do planeta ao corpo-teste).

\section{Considerações finais}

Ao analisar a realidade escolar nos deparamos com o ensino de um saber fragmentado, onde as ciências são ensinadas de forma totalmente esquematizadas, repletas de equações padronizadas; tendo como consequência, a "formação" de estudantes meramente repetidores de uma ciência pouco fundamentada, incapazes de refletir sobre a rigidez e a veracidade de uma ampla gama de valores que lhes estão sendo somente transmitidos, sem saberes construídos. Feyerabend ( 1985, p.456) já dizia:

A sociedade moderna é 'copernicana', mas não porque a doutrina de Copérnico haja sido posta em causa, submetida a um debate democrático e então aprovada por maioria simples; é 'copernicana' porque os cientistas são copernicanos e porque lhes aceitamos a cosmologia tão arcaicamente quanto, no passado, se aceitou a cosmologia de bispos e cardeais.

Com os avanços tecnológicos os computadores passaram a fazer parte do dia a dia dos jovens e adultos. Acreditamos que a utilização da história da ciência, evidenciando seus aspectos epistemológicos, é extremamente importante para a formação de uma cultura científica ligada ao uso de novas tecnologias como forma de desenvolver poderosas ferramentas didáticas para o ensino de ciências.

Democratizar o espaço dos saberes informais em blogosferas pode estimular uma aprendizagem mais dinâmica, eficaz e criativa. 


\section{Referências bibliograficas}

ALBANESE, A.; NEVES, M. C. D. ;. VICENTINI, M. Report sulle idee degli studenti sui fenomeni di movimento. Roma, LDS, 1997.

ALGODOO. Disponível em: http://www.algodoo.com/download , 2014.

BRONOWSKI . As origens do conhecimento e da imaginação. Brasília, UnB,1985.

BRYAN, C.D.B. The National Geographical Society: 100 Years of Adventure and Discovery. New York: Harry N. Abrahams Inc., 1987.

BRUNER, J. The Process of Education. Cambridge: Harvard U.P., 1961.

DANHONI NEVES, M.C. e NEVES, A.C.D. An Ideographic and Nomothetic Comprehension of the nature of science by science teachers. In: BANDIERA et al. Research in Science Education in Europe: The picture expands. Roma: Litoflash. $2^{\text {nd }}$ edition, 2010.

FÍSICA - PSSC. Brasília: Editora Universidade de Brasília, 1964.

FEYERABEND, P.K. Contra o Método. Rio de Janeiro: Francisco Alves, 1985.

GALILEI, Galileu. Duas novas ciências. 2.ed. São Paulo: Nova Stella, 1988.

GOODSTEIN, D. et al.The Mechanical Universe. Cambridge: Cambridge University Press, 1989.

NEVES, M. C. D. A história da ciência no ensino de física. Ciência e Educação, v. 5, n.1, p.73-81, 1998.

PHYSICS: CINEMA CLASSICS. Videodiscs produced by American Association of Physics Teaching. New York: College Park, 1992.

PROJECTO FÍSICA (Harvard Project Physics). Lisboa: Fundação Calouste Gulbenkian, 1980.

SAGAN, C. Cosmos. Rio de Janeiro: Francisco Alves, 1980.

SAVI, A.A. et al. Laboratorio de Criação Visual. Maringá :UEM, 2002.

VICENTINI, M. et al. Fisica. Roma: RAI/Università "La Sapienza" di Roma, 1980.

VIENNOT, L. Le raisonement spontané en dynamique élémentaire. Paris, Herman, 1979.

ZA'ROUR, G.I. Science misconceptions among certain groups of students in Lebanon. Journal of Research in Science Teaching, v.12, p. 385-392, 1975.

ZOLlMAN, D. A. Teaching and Learning Physics with Interactive Video. Website: http://www.phys.ksu.edu/perg/dvi/pt/intvideo.html , 2002.

Informações complementares dos autores:

-Eloá dei Tós Germano: Docente do Departamento de Física na UEM, Mestranda no PPGECT do Câmpus Ponta Grossa da UTFPR, e-mail: eloagermano@ gmail.com .

-Ana Claudia Danhoni Neves: Docente do Departamento de Física na UEM, Mestranda no PPGECT do Câmpus Ponta Grossa da UTFPR, e-mail : ananeves@ hotmail.com .

-Josie Agatha Parrilha da Silva: Docente do Departamento de Artes na UEPG e no Programa de Pós-Graduação em Ensino de Ciências e Tecnologia do Câmpus Ponta Grossa da UTFPR, e-mail: josieaps@hotmail.com . 